\title{
Robotic renal surgery for renal cell carcinoma with inferior vena cava thrombus
}

\author{
Selma Masic, Marc C. Smaldone \\ Fox Chase Cancer Center, Philadelphia, PA, USA \\ Contributions: (I) Conception and design: All authors; (II) Administrative support: All authors; (III) Provision of study materials or patients: All \\ authors; (IV) Collection and assembly of data: All authors; (V) Data analysis and interpretation: All authors; (VI) Manuscript writing: All authors; (VII) \\ Final approval of manuscript: All authors. \\ Correspondence to: Selma Masic, MD. Fox Chase Cancer Center, Philadelphia, PA, USA. Email: selma.masic@fccc.edu.
}

\begin{abstract}
Surgical management of renal cell carcinoma (RCC) with inferior vena cava (IVC) thrombus is inherently complex, posing challenges for even the most experienced urologists. Until the mid-2000s, nephrectomy with IVC thrombectomy was exclusively performed using variations of the open technique initially described decades earlier, but since then several institutions have reported their robotic experiences. Robotic IVC thrombectomy was initially reported for level I and II thrombi, and more recently in higherlever III thrombi. In general, the robotic approach is associated with less blood loss and shorter hospital stays compared to the open approach, low rates of open conversion in reported cases, relatively low rates of high-grade complications, and favorable overall survival on short-term follow-up in limited cohorts. Operative times are longer, costs are significantly higher, and left-sided tumors always require intraoperative repositioning and usually require preoperative embolization. To date, criteria for patient selection or open conversion have not been defined, and long-term oncologic outcomes are lacking. While the early published robotic experience demonstrates feasibility and safety in carefully selected patients, longer-term follow-up remains necessary. Patient selection, indications for open conversion, logistics of conversion particularly in emergent settings, necessity and safety of preoperative embolization, the value proposition, and long-term oncologic outcomes must all be clearly defined before this approach is widely adopted.
\end{abstract}

Keywords: Renal cell carcinoma (RCC); nephrectomy; inferior vena cava thrombectomy (IVC thrombectomy); minimally invasive surgery

Submitted May 21, 2019. Accepted for publication Jun 04, 2019.

doi: $10.21037 /$ tau.2019.06.15

View this article at: http://dx.doi.org/10.21037/tau.2019.06.15

The rationale for aggressive surgical management of renal cell carcinoma (RCC) with inferior vena cava (IVC) involvement was first formally described in 1972 by Skinner et al. at Massachusetts General Hospital, at which time the surgical principles for the procedure were established and described (1). Prior to this, IVC thrombectomy was rarely undertaken given the poor prognosis associated with the advanced stage of disease. Decades passed with few changes to the operative technique until the mid-2000s and the burgeoning adoption of robotics in urologic surgery. Pure or hand-assisted laparoscopic radical nephrectomy for level II thrombi was initially described in scattered case reports $(2,3)$, but the cases were limited in number and involved only early level II thrombi extending between $1-3 \mathrm{~cm}$ above the renal vein. Starting in 2011, several groups began reporting outcomes of IVC thrombectomy using the robotic approach, and since then thrombus levels and surgical complexity have been increasing (Figure 1).

In 2011, Abaza et al. published an initial series of five patients who underwent robotic IVC thrombectomy by a single surgeon. Thrombi protruded between $1-5 \mathrm{~cm}$ into the IVC, and all cases required cross-clamping and cavotomy with reconstruction. Operative times were relatively long, median 327 minutes (range, 240-411 minutes), but in this 


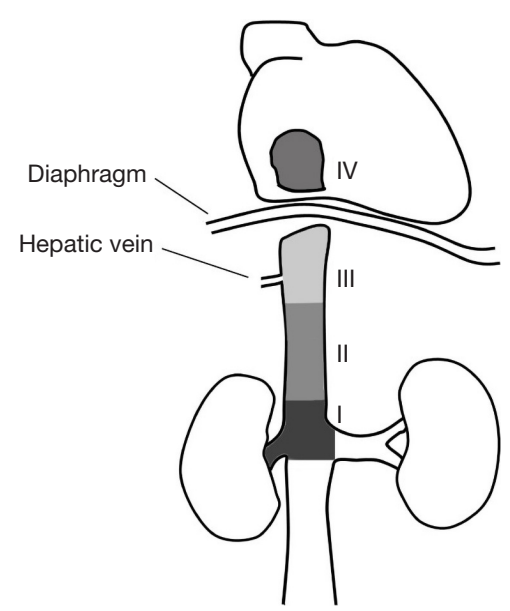

Figure 1 Mayo thrombus classification; image unmodified from original publication: prognostic benefit of surgical management in RCC patients with thrombus extending to the renal vein and IVC: 17-year experience at a single center-Scientific Figure on ResearchGate. Available online: https://www.researchgate.net/ figure/Classification-of-tumor-thrombus-level-according-to-theMayo-staging-system-Level-0_fig1_257812494. IVC, inferior vena cava; RCC, renal cell carcinoma.

early series, patients generally did well with short lengths of stay, mean 1.2 days (range, 1-2 days), and no significant complications. In 2015, robotic management of level III thrombi was reported, but cohort size remained limited $(4,5)$. Gill and colleagues published an initial series of 16 cases, 9 of which were level III without open conversion or mortality. The median operative time was 294 minutes (range, 270-378 minutes), and median hospital stay 4.5 days. Angioembolization was carried out preoperatively in patients with left-sided and/or large tumors, collateralized vessels, or arterialized thrombi (5). Earlier in the same year, Bratslavsky and Cheng published a case report of a single level III rightsided thrombus and retroperitoneal lymph node dissection. The total operative time was 366 minutes and the hospital stay was 3 days. The patient recovered well without postoperative complications.

After the initial robotic experience for high-level thrombi, several groups have published on outcomes, but even multi-institutional studies have included relatively small cohorts and limited level III thrombi (6-9). In 2016, Abaza et al. reported on 32 cases performed by nine surgeons across nine institutions (6). A total of 30 level II and only two level III thrombi were included in the cohort. Caval tumor lengths ranged widely from 1-11 cm (median $4.2 \mathrm{~cm}$ ). Twenty-four of the cases required crossclamping, mean operative time was 292 minutes (range,
180-411 minutes), mean EBL was $399 \mathrm{~mL}$ (range, 25$2,000 \mathrm{~mL}$ ), and mean hospital stay was 3.2 days (range, 1-7 days). None of the cases resulted in open conversion or mortality. The following year, Chopra et al. reported 1-year outcomes of an additional 25 selected patients with level II and III thrombi (9). They stressed that a uniform and reproducible surgical approach was imperative for reliable and safe outcomes and reiterated the previously defined "IVC-first, kidney-last" technique. The goal of the technique is to minimize thrombus embolism and major hemorrhage. Tumor thrombus embolism is minimized through minimal IVC manipulation and dissection of tissue away from the IVC rather than vice versa. Twenty-four of the patients were successfully completed while one was converted to open, and of the remaining cases, 11 were level III thrombi. Staplers are fired across the renal vein and associated tumor thrombus on right- and left-sided cases. Management of left-sided tumors is more complex than right and requires not only preoperative angioembolization but also intraoperative repositioning from the left lateral decubitus position (left side down during caval work) (Figure 2) to the right lateral position (left side up) for the nephrectomy portion of the case. In this series, 20 patients $(80 \%)$ underwent preoperative renal artery embolization. At one year, four patients (16.7\%) had a complication including deep vein thrombosis $(\mathrm{n}=1)$, pulmonary embolus $(\mathrm{n}=1)$, chylous ascites $(\mathrm{n}=1)$, and subphrenic abscess $(\mathrm{n}=1)$. At a median follow up of 16 months (range, 12-39 months), overall survival (OS) was 100\%, 11 (46\%) developed new metastases, and $10(42 \%)$ received adjuvant therapy.

The series published to date have emphasized the reproducibility and safety of the robotic technique given reassuring outcomes from retrospective series. While published studies have clearly included very carefully selected patients, clear selection criteria have yet to be defined in the literature. Intraoperative factors that lead to open conversion have similarly not been defined. Failure to progress "due to insurmountable bowel loops" was reported as a reason for open conversion in the recent series by Chopra et al. (9), but most other series have not discussed converted cases. Management of major complications that require intraoperative consultation from vascular, hepatic, or cardiac surgeons may not be possible robotically, necessitating open conversion as robotic experience across specialties and institutions is highly variable (Table 1).

Long-term oncologic outcomes are lacking given the novelty of the procedure and relatively limited cohorts in published literature. The previously discussed study by Chopra et al. published 1-year outcomes (9), but most others have not reported outcomes outside of the 
initial postoperative period. Whether stapling across the thrombus-containing renal vein or tumor spillage in the setting of pneumoperitoneum have effect on long-term oncologic outcomes is not yet known. Long-term outcomes of preoperative renal artery embolization have also previously been called into question. A 2,009 retrospective series by Subramanian et al. reported on a unique cohort in which $60 \%(\mathrm{n}=135 / 225)$ of the patients underwent

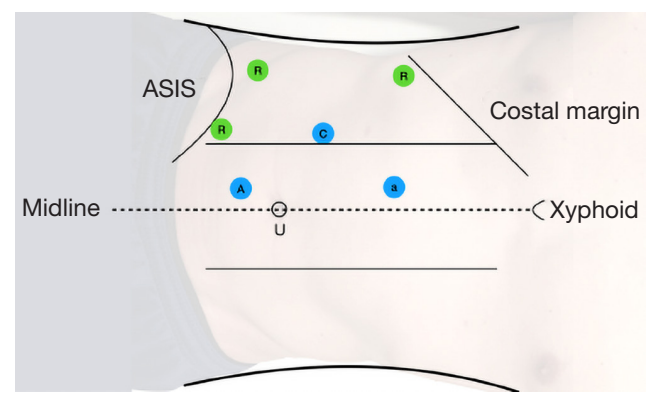

Figure 2 Positioning for caval thrombectomy and right-sided nephrectomy in the left lateral decubitus position, right side up. Left-sided nephrectomy requires subsequent repositioning into the right lateral decubitus position and port replacement for the left robotic nephrectomy. C, camera; U, umbilicus; A, $12 \mathrm{~mm}$ assist port; a, $5 \mathrm{~mm}$ assist port; $\mathrm{R}, 8 \mathrm{~mm}$ robotic bariatric port. preoperative embolization. They found that patients who underwent embolization prior to open radical nephrectomy and IVC thrombectomy had higher rates of transfusion, longer operative time, more postoperative complications, longer ICU stays, and interestingly, even increased preoperative mortality $(13 \%$ vs. $3 \%, \mathrm{P}=0.017)(10)$. As $67 \%$ of the embolized patients had level III and IV thrombi compared to $48 \%$ of the non-embolized patients $(\mathrm{P}=0.032)$, multivariable analyses adjusting for thrombus level and other clinical variables were performed which demonstrated a persistent association between embolization and increased perioperative mortality (OR 5.5, 95\% CI: $1.2-25.6, \mathrm{P}=0.029)$. Though these are findings from a single retrospective study, the cohort size is still larger than the robotic series published to date, and the findings deserve attention and further study.

As urologic operative techniques continue to evolve, determining whether the new techniques contribute to progress and not merely novelty, will be of paramount importance. To date, there are no prospective randomized trials comparing robotic and open IVC thrombectomy, but recent trials for cystectomy have not shown superior outcomes for the robotic approach but have revealed significantly higher costs $(11,12)$. As national healthcare costs are already staggeringly high and rising, the value of

Table 1 Summary of published outcomes of robotic nephrectomy and IVC thrombectomy

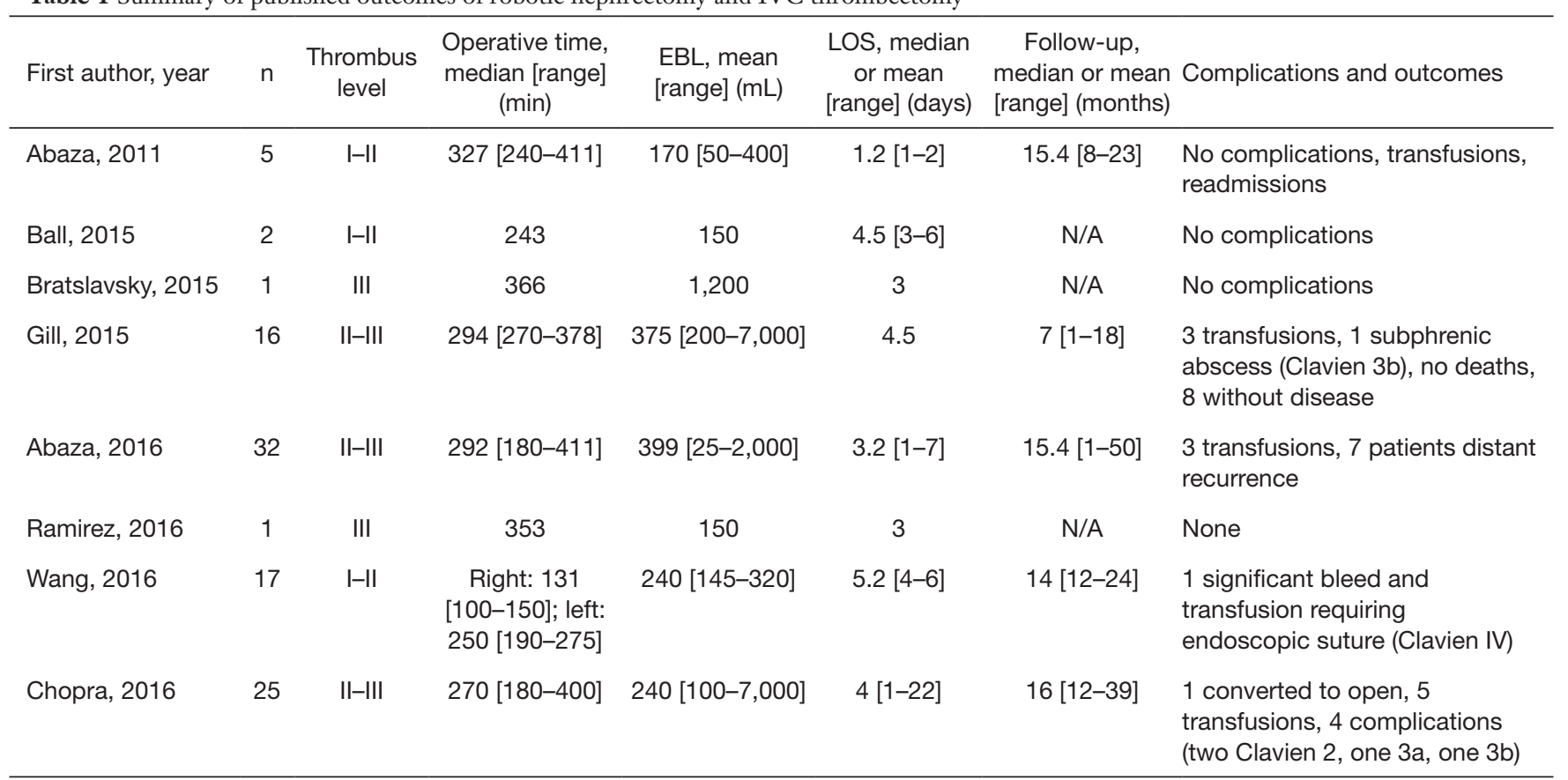

N/A, not applicable; IVC, inferior vena cava; EBL, estimated blood loss; LOS, length of stay. 
robotics must be carefully evaluated for specific urologic operations, because the benefits may not be equal or worthwhile across all procedures. The early published robotic experience demonstrates that robotic IVC thrombectomy performed by gifted minimally invasive surgeons is feasible in select patients, but as we continue to move forward, defining selection criteria, indications for and logistics of open conversion, necessity and safety of preoperative embolization, cost versus value, and most crucially intermediate- and long-term oncologic outcomes will be of utmost importance. Until these data are available and the procedure becomes more reproducible, open radical nephrectomy with IVC thrombectomy will remain the standard of care for locally advanced RCC.

\section{Acknowledgments}

Funding: None.

\section{Footnote}

Provenance and Peer Review: This article was commissioned by the editorial office, Translational Andrology and Urology for the series "Controversies in Minimally Invasive Urologic Oncology". The article has undergone external peer review.

Conflicts of Interest: Both authors have completed the ICMJE uniform disclosure form (available at http://dx.doi. org/10.21037/tau.2019.06.15). The series "Controversies in Minimally Invasive Urologic Oncology" was commissioned by the editorial office without any funding or sponsorship. Marc C. Smaldone served as the unpaid Guest Editor of the series. The authors have no other conflicts of interest to declare.

Ethical Statement: The authors are accountable for all aspects of the work in ensuring that questions related to the accuracy or integrity of any part of the work are appropriately investigated and resolved.

Open Access Statement: This is an Open Access article distributed in accordance with the Creative Commons Attribution-NonCommercial-NoDerivs 4.0 International License (CC BY-NC-ND 4.0), which permits the noncommercial replication and distribution of the article with the strict proviso that no changes or edits are made and the original work is properly cited (including links to both the formal publication through the relevant DOI and the license). See: https://creativecommons.org/licenses/by-nc-nd/4.0/.

\section{References}

1. Skinner DG, Pfister RF, Colvin R. Extension of renal cell carcinoma into the vena cava: the rationale for aggressive surgical management. J Urol 1972;107:711-6.

2. Romero FR, Muntener M, Bagga HS, et al. Pure laparoscopic radical nephrectomy with level II vena caval thrombectomy. Urology 2006;68:1112-4.

3. Kovac JR, Luke PP. Hand-assisted laparoscopic radical nephrectomy in the treatment of a renal cell carcinoma with a level II vena cava thrombus. Int Braz J Urol 2010;36:327-31.

4. Bratslavsky G, Cheng JS. Robotic-assisted Radical Nephrectomy With Retrohepatic Vena Caval Tumor Thrombectomy (Level III) Combined With Extended Retroperitoneal Lymph Node Dissection. Urology 2015;86:1235-40.

5. Gill IS, Metcalfe C, Abreu A, et al. Robotic Level III Inferior Vena Cava Tumor Thrombectomy: Initial Series. J Urol 2015;194:929-38.

6. Abaza R, Shabsigh A, Castle E, et al. Multi-Institutional Experience with Robotic Nephrectomy with Inferior Vena Cava Tumor Thrombectomy. J Urol 2016;195:865-71.

7. Ramirez D, Maurice MJ, Cohen B, et al. Robotic Level III IVC Tumor Thrombectomy: Duplicating the Open Approach. Urology 2016;90:204-7.

8. Wang B, Li H, Ma X, et al. Robot-assisted Laparoscopic Inferior Vena Cava Thrombectomy: Different Sides Require Different Techniques. Eur Urol 2016;69:1112-9.

9. Chopra S, Simone G, Metcalfe C, et al. Robot-assisted Level II-III Inferior Vena Cava Tumor Thrombectomy: Step-by-Step Technique and 1-Year Outcomes. Eur Urol 2017;72:267-74.

10. Subramanian VS, Stephenson AJ, Goldfarb DA, et al. Utility of preoperative renal artery embolization for management of renal tumors with inferior vena caval thrombi. Urology 2009;74:154-9.

11. Bochner BH, Dalbagni G, Sjoberg DD, et al. Comparing Open Radical Cystectomy and Robot-assisted Laparoscopic Radical Cystectomy: A Randomized Clinical Trial. Eur Urol 2015;67:1042-50.

12. Parekh DJ, Reis IM, Castle EP, et al. Robot-assisted radical cystectomy versus open radical cystectomy in patients with bladder cancer (RAZOR): an open-label, randomised, phase 3, non-inferiority trial. Lancet 2018;391:2525-36.

Cite this article as: Masic S, Smaldone MC. Robotic renal surgery for renal cell carcinoma with inferior vena cava thrombus. Transl Androl Urol 2021;10(5):2195-2198. doi: 10.21037/tau.2019.06.15 